\title{
The Farahat sodium natural convection film boiling experiment revisited
}

\author{
Georges Berthoud ${ }^{1}$ GBExper, 8 rue Champ Rochas, 38240 Meylan, France \\ Alix Le Belguet ${ }^{2}$ CEA Cadarache DTN/SMTA/LPMA 13108 Saint-Paul-Lez-Durance \\ Magali Zabiégo CEA Cadarache DTN/SMTA/LPMA 13108 Saint-Paul-Lez-Durance
}

\begin{abstract}
With the renewal of interest for sodium-cooled fast reactors, looking at what is known from the past, it appears - in the frame of severe accident studies in general and $\mathrm{FCl}$ in particular, that very few is known about sodium film boiling around hot fuel droplets which is a condition allowing premixing. The past Farahat experiment [8], performed in 1971, in which hot solid spheres were transferred into sodium has been revisited. Looking in the detailed results, it appears that a phenomena has been ignored, i.e. the existence of two film boiling regimes as observed in similar experiments with water $[5,6]$. These two film boiling regimes have been analyzed since the transition between these regimes could lead to the onset of spontaneous explosions if the melt is still liquid at this transition. A simple model has been built for the estimation of this transition point. As this model is able to describe the transition observed in $\mathrm{Sn}-\mathrm{H}_{2} \mathrm{O}$ experiments [7], it has been used for $\mathrm{UO}_{2}-\mathrm{Na}$ systems.
\end{abstract}

\section{INTRODUCTION}

With the renewal of interest for sodium-cooled fast reactors (Generation IV), it is interesting to look at what knowledge is missing or has to be improved in that area. In the frame of severe accident studies, one point of importance is the consequences of large scale Fuel Coolant Interactions ( $\mathrm{FCl}$ ) which may occur after core melting. From the 1990's, it is recognized that large scale FCls are possible with sodium as coolant [1]. The main difference with FCls with water lies in the difficulty to mix large masses of fuel with sodium due to the difficulty to get very stable film boiling with subcooled sodium. In fact, in most of the tests, multiple interactions were observed while fuel was introduced into the coolant. However, with sodium close to saturation, the $\mathrm{FCl}$ behavior looks very similar with both coolants. This can occur with sodium initially close to saturation during the accident sequence or sodium being progressively heated during successive $\mathrm{FCls}$ [1].

It is then interesting to study the film boiling stability of heated spheres plunged into sodium. In fact, in similar experiments with water, see [2] for example, under certain circumstances, during quenching in the film boiling regime, there is first a low cooling rate regime (see for example the red curve in Figure 1: for point $\mathrm{D}$, the superheat is greater than $750^{\circ} \mathrm{C}$ and the cooling rate is about $\left.2.6 \mathrm{MW} / \mathrm{m}^{2}\right)$, followed by a rapid increase towards a large heat flux $\left(\sim 8 \mathrm{MW} / \mathrm{m}^{2}\right.$ after point $\mathrm{E}$ on the red curve) then followed by a small decrease of the flux (point $E$ to point $F$ ) as in usual boiling curved.

\footnotetext{
${ }^{1}$ Corresponding Author

${ }^{2}$ Now: EDF Lab Paris-Saclay 7, Blvd Gaspard Monge 91120 Palaiseau
} 


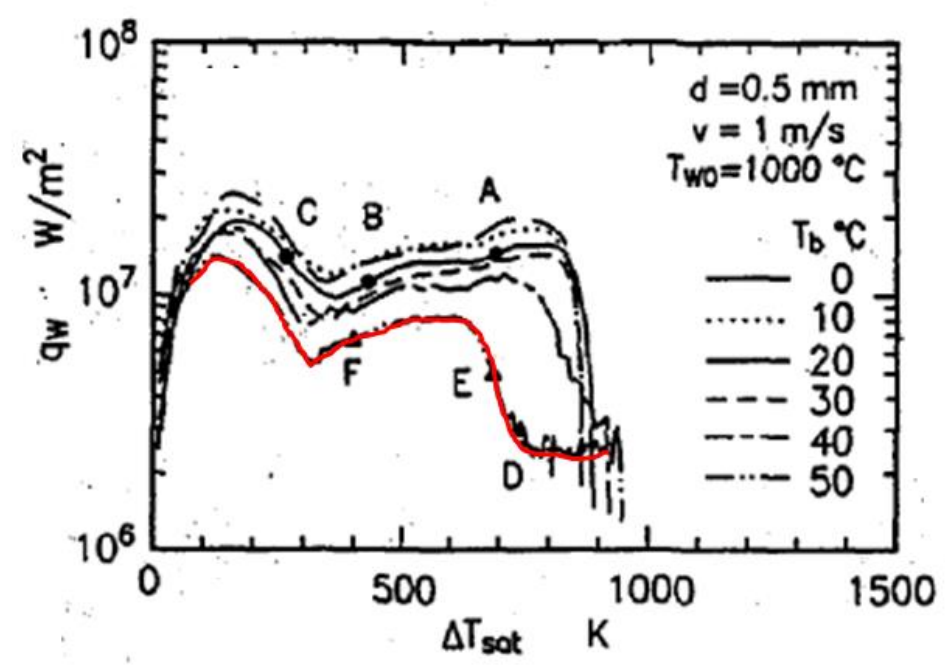

Figure 1: Boiling curves according to coolant temperature in Honda et al. [2]

It was reported that such a behavior was favored by high superheats, low subcoolings, small diameters and low relative velocities. In [3], it was added that it was also favored by high pressures.

In [3], it was also proposed that this type of behavior, i.e. transition from a low heat flux boiling regime towards a higher heat flux film boiling regime, was associated with the appearance of instabilities at the vapor liquid interface during quenching leading to transient liquid-solid contacts and/or small droplet entrainment towards the rear region, both mechanisms increasing heat transfer. In fact, these local and intermittent liquid-solid contacts have been "measured" in references [4] and [5].

More recently, these two regimes have also been observed in some experiments in which hot $\left(600^{\circ} \mathrm{C}\right)$ solid spheres are dipped into water [5]. From the temperature evolution of the spheres, the heat flux curves are deduced. Results for two diameter sizes $(16$ and $32 \mathrm{~mm})$ show very different behaviors as shown in Figure 2:

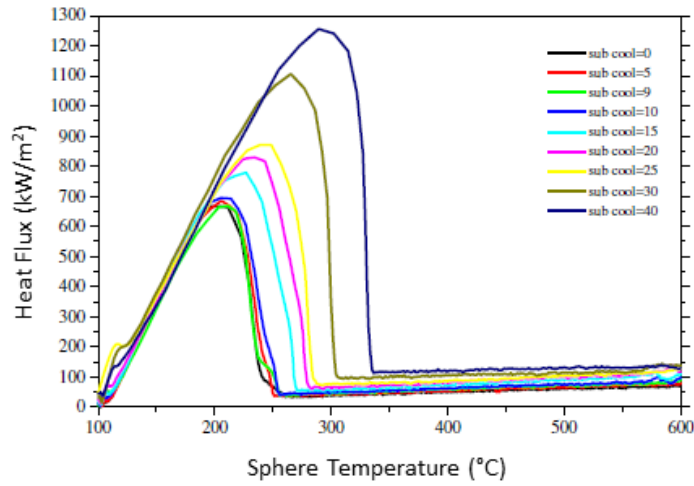

a. Sphere diameter $=16 \mathrm{~mm}$

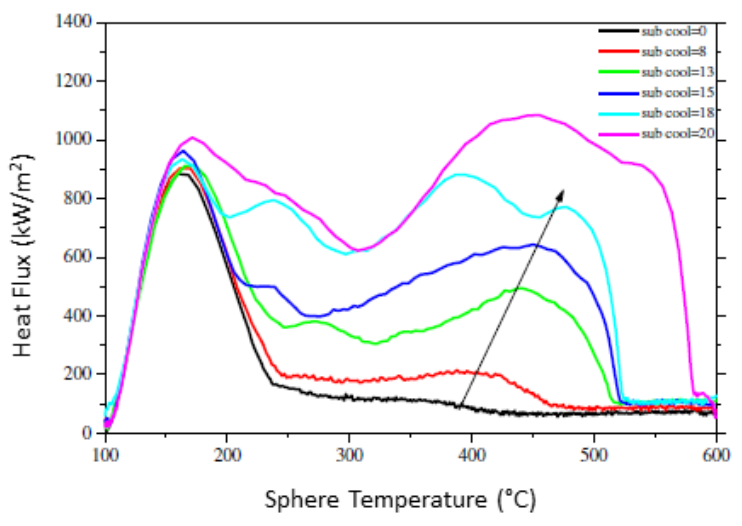

b. Sphere diameter $=32 \mathrm{~mm}$

Figure 2: Sphere heat flux versus sphere temperature during quenching for different water subcoolings (Figures 6 and 7 from [6]) 
In Figure 2a, for the $16 \mathrm{~mm}$ diameter sphere, are found classical boiling curves with an abrupt transition towards transition boiling at the usual minimum film boiling temperature. While for the 32 $\mathrm{mm}$ diameter sphere (Figure $2 \mathrm{~b}$ ), it is observed that above a certain subcooling, film collapsing noise and higher heat transfer rates are observed after some period of low heat fluxes.

This explanation is also supported by the single droplet $\mathrm{FCl}$ experiments of Reynolds [7] exploring the Temperature Interaction Zone (TIZ), the domain in the plane "initial droplet temperature - initial coolant temperature" where spontaneous (i.e. without trigger) interactions were observed. Such a TIZ is reported in Figure 3.

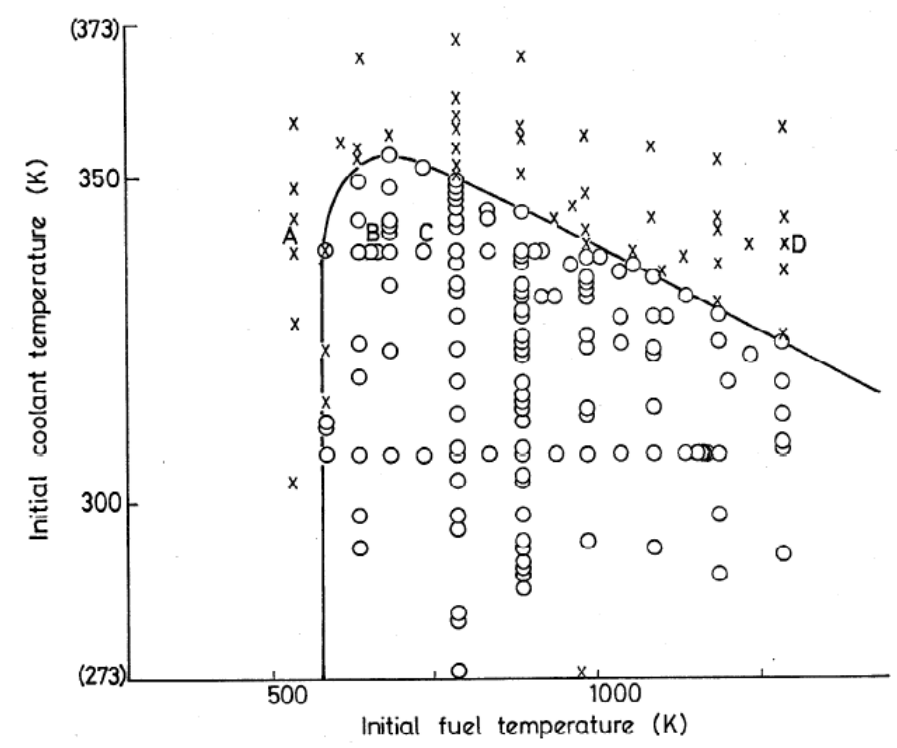

Figure 3: Fuel-coolant interaction zone for $1.210^{-2} \mathrm{~kg}$ of tin dropped into water ( 0 indicates interaction, $\mathrm{X}$ indicates no interaction) (Figure 5 from [7])

For Reynolds et al., the diagonal boundary of the measured TIZ is associated to the transition between a "thick film regime" and a "thin film regime" during which some coolant comes into contact with the liquid fuel, contacts leading to the explosion.

If we apply these ideas to $\mathrm{FCl}$ studies for nuclear reactors, it appears that a thermal destabilization of the vapor film would appear at a fuel temperature such that the fuel has been solidified for a long time for water-cooled reactors. However, it appears to be desirable to study this for sodium-cooled nuclear reactors. It is the reason why we have revisited the only sodium film boiling experiment around a sphere i.e. the Farahat one [8], performed in 1971.

\section{The Farahat natural convection film boiling experiment in sodium [8]}

\subsection{Experimental set-up}




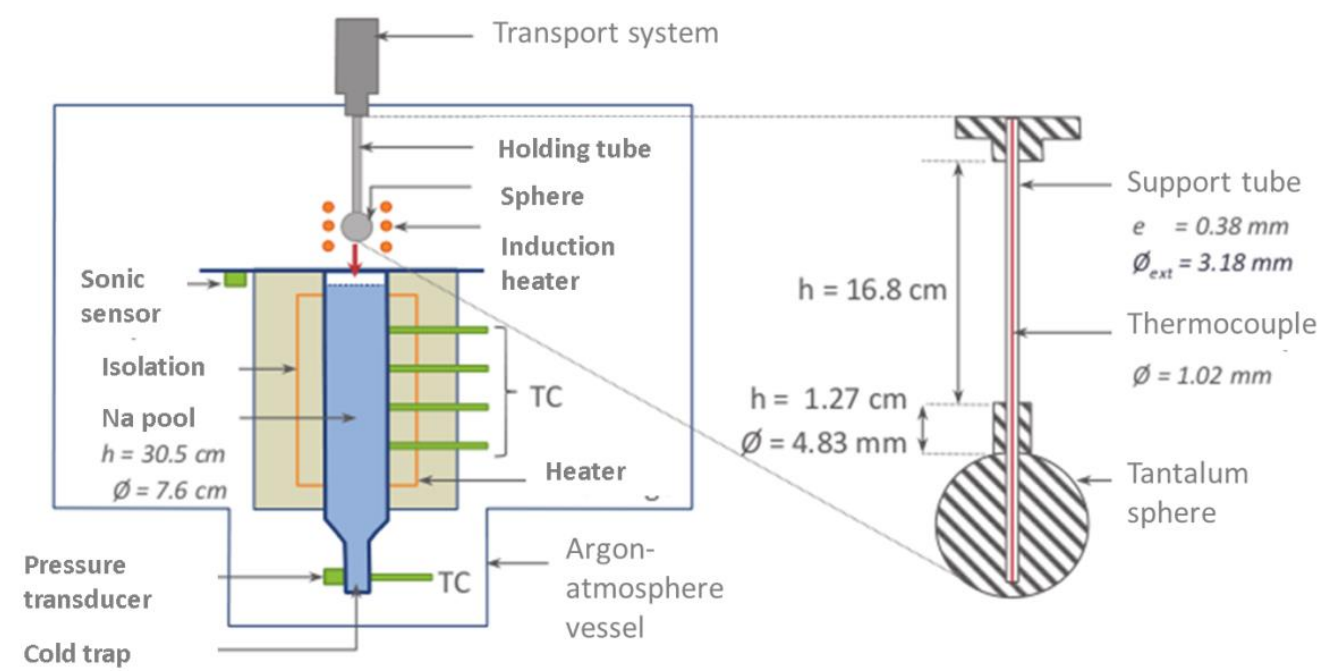

Figure 4: Farahat experimental set-up

In this experiment, a tantalum sphere (diameter $D_{s}$ from $12.7 \mathrm{~mm}$ to $25.4 \mathrm{~mm}$ ) is heated in an induction oven up to $2334 \mathrm{~K}$ and plunged into a subcooled sodium pool (subcooling from $4.1 \mathrm{~K}$ to 29.1K). A thermocouple located close to the bottom surface of the sphere allows, through conduction calculations, the evaluation of the heat flux lost by the sphere.

Unfortunately, the presence of the support rod with a diameter $d_{\text {rod, }}$, not negligible according to the sphere diameter, disturbs the flow at the rear part of the sphere, increasing heat transfer. To take this into account, it is possible to use the correction proposed by Hässler [9], based on natural convection film boiling experiments in water around a heated sphere, who proposed a corrected Nusselt number according to :

$$
N u_{\text {corrected }}=\frac{N u_{\text {experimental }}}{1+3.2 \frac{d_{\text {rod }}}{D_{s}}}
$$

Which leads, for the Farahat results, to:

\begin{tabular}{|c|c|c|}
\hline $\mathbf{D}_{\mathbf{s}}(\mathbf{m m})$ & $\mathbf{d}_{\text {rod }} / \mathbf{D}_{\mathbf{s}}$ & $\mathrm{Nu}_{\text {experimental }} / \mathrm{Nu}_{\text {corrected }}$ \\
\hline 12.7 & 0.38 & 2.22 \\
\hline 19.1 & 0.25 & 1.80 \\
\hline 25.4 & 0.19 & 1.61 \\
\hline
\end{tabular}

This correction has then to be compared to the $10 \%$ experimental error given by Farahat. The correction may even be larger if we take into account the presence of the tantalum cylinder (diameter $4.83 \mathrm{~mm}$, height $12.7 \mathrm{~mm}$ ) located at the top of the sphere.

\subsection{Experimental results and analysis}

In the following table are presented the experimental conditions and results of the 16 tests in which film boiling has been observed, i.e. for sphere temperatures higher than $1802 \mathrm{~K}$ and sodium temperatures higher than $1123 \mathrm{~K}$ (subcooling $\Delta \mathrm{T}_{\text {sub }}<29.1 \mathrm{~K}$ ). 


\begin{tabular}{|c|c|c|c|c|c|c|c|c|c|c|c|}
\hline Test & $\begin{array}{l}D_{s} \\
(\mathrm{~cm})\end{array}$ & $\begin{array}{l}T_{\mathrm{S}, 0} \\
(\mathrm{~K})\end{array}$ & $\begin{array}{c}\Delta \mathbf{T}_{\text {Sat }, 0} \\
\text { (K) }\end{array}$ & $\begin{array}{l}T_{\mathrm{L}} \\
(\mathrm{K}) \\
\end{array}$ & $\begin{array}{c}\Delta \mathbf{T}_{\text {Sub }} \\
\text { (K) }\end{array}$ & $\begin{array}{c}\mathbf{h}_{\mathbf{s}} \\
(\mathrm{cm})\end{array}$ & $\begin{array}{l}T_{\text {eb }} \\
(\mathrm{s})\end{array}$ & $\begin{array}{l}\mathbf{t}_{\text {film }} \\
(\mathrm{s})\end{array}$ & $\begin{array}{c}\Delta \mathbf{T}_{\text {Sat, } 1} \\
(\mathrm{~K})\end{array}$ & $\begin{array}{c}\mathbf{q}_{\text {max,exp }} \\
\left(10^{5} \mathrm{~W} / \mathrm{m}^{2}\right)\end{array}$ & $\begin{array}{c}h_{\text {max,exp }} \\
\left(\mathrm{W} \cdot \mathrm{m}^{-2} \cdot \mathrm{K}^{-1}\right)\end{array}$ \\
\hline 28 & 2.54 & 1802.6 & 650.3 & 1148.2 & 4.1 & 11.4 & 16.8 & 1.5 & 567.6 & 4.53 & 798.3 \\
\hline 27 & 2.54 & 2179.3 & 1027.0 & 1148.2 & 4.1 & 11.4 & 40.4 & 21.6 & 979.8 & 4.50 & 459.7 \\
\hline 26 & 2.54 & 2259.3 & 1107.0 & 1148.2 & 4.1 & 11.4 & 43.6 & 25.05 & 1002.8 & 5.05 & 503.3 \\
\hline 25 & 2.54 & 2418.7 & 1266.4 & 1148.2 & 4.1 & 11.4 & 53 & 36.25 & 1188.5 & 6.82 & 573.7 \\
\hline 41 & 1.27 & 2522.0 & 1369.8 & 1148.2 & 4.1 & 11.4 & 22.8 & 15.6 & 1234.0 & 7.61 & 616.6 \\
\hline 36 & 2.54 & 2474.8 & 1322.5 & 1138.2 & 14.1 & 7.6 & 53.3 & 36.9 & 1263.5 & 6.70 & 530.2 \\
\hline 42 & 1.27 & 2587.0 & 1434.8 & 1138.2 & 14.1 & 11.4 & 17.9 & 13.1 & 1280.5 & 8.77 & 684.5 \\
\hline 35 & 2.54 & 2466.5 & 1314.2 & 1138.2 & 14.1 & 11.4 & 47.6 & 32 & 1292.5 & 7.14 & 552.6 \\
\hline 38 & 1.91 & 2526.5 & 1374.2 & 1148.2 & 4.1 & 11.4 & 41.2 & 27.6 & 1293.8 & 8.13 & 628.2 \\
\hline 32 & 2.54 & 2473.7 & 1321.4 & 1143.2 & 9.1 & 11.4 & 54.6 & 37 & 1299.4 & 7.74 & 596.0 \\
\hline 29 & 2.54 & 2585.9 & 1433.7 & 1148.2 & 4.1 & 11.4 & 57.4 & 40.15 & 1371.9 & 10.4 & 757.5 \\
\hline 33 & 2.54 & 2494.3 & 1342.0 & 1133.2 & 19.1 & 11.4 & 44.9 & 27.7 & 1374.1 & 8.39 & 610.8 \\
\hline 24 & 2.54 & 2585.9 & 1433.7 & 1148.2 & 4.1 & 11.4 & 61.3 & 43 & 1394.7 & 9.77 & 700.7 \\
\hline 39 & 1.91 & 2577.6 & 1425.3 & 1143.2 & 9.1 & 11.4 & 36.4 & 24.25 & 1399.9 & 14.1 & 1006.8 \\
\hline 43 & 1.27 & 2633.7 & 1481.4 & 1123.2 & 29.1 & 11.4 & 11.8 & 7.9 & 1419.5 & 78.5 & 5526.7 \\
\hline 30 & 2.54 & 2607.6 & 1455.3 & 1123.2 & 29.1 & 11.4 & 21.5 & 18 & 1458.5 & 12.2 & 837.5 \\
\hline
\end{tabular}

Table 1: Experimental conditions and results of the film boiling tests of Farahat

$\left(D_{s}=\right.$ sphere diameter, $T_{s, 0}=$ Initial sphere temperature, $\Delta T_{s a t, 0}=T_{s, 0}-T_{s a t} ; T_{L}=$ initial sodium temperature ; $\Delta T_{\text {sub }}=T_{\text {sat }}-T_{L} ; H_{s}=$ immersion height $; t_{e b}$ : boiling time $; t_{\text {film }}=$ duration of the film boiling regime $; \Delta T_{\text {sat }, 1}=$ sphere superheat at the time of the observed maximum heal flux $q_{\max \text {, exp }}$ associated with the maximum heat transfer coefficient $h_{\text {max,exp }}$ )

Analyzing in details the results reported in Farahat thesis, it appears that the raw experimental curves have been smoothed as shown in Figure 5:

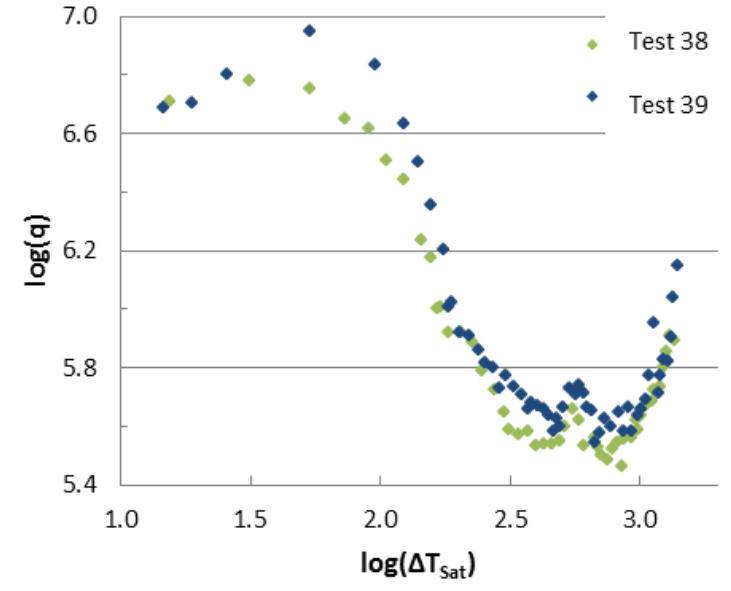

a. Raw experimental data

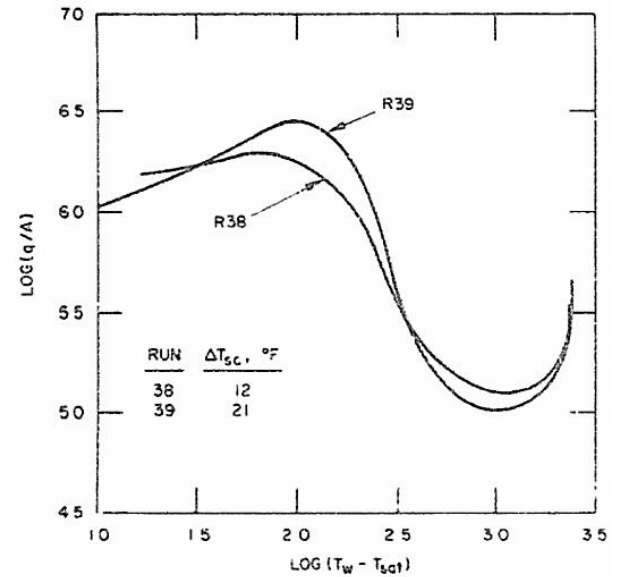

b. Smoothed experimental data

Figure 5: Boiling curves for Farahat tests 38 and 39 before and after being smoothed

Zooming on the results of Farahat test 39 (Figure 6), something appears which looks similar to the two film boiling regimes observed in the Honda et al. experiments. 


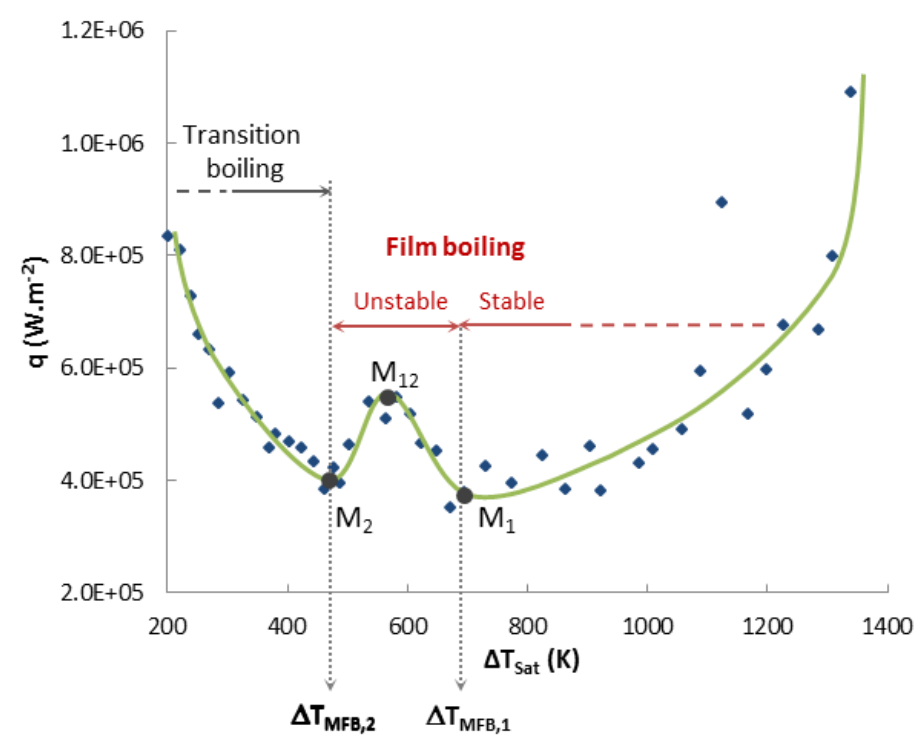

Figure 6 : Observation of two film boiling regimes in Farahat test 39

These two film boiling regimes are not observed for the low superheat tests ( 27 and 28 ) and high subcooling tests ( 30 and 43 ). But, for the other tests, two minimum are observed in the boiling curves during the sphere cooling:

- the first one (point $M_{1}$, Figure 6) could correspond to the appearance of liquid-solid contacts, then increasing the heat flux in solid-liquid systems, but that can lead to spontaneous $\mathrm{FCl}$ in the case of liquid-liquid systems as observed, for example, in the tin-water experiments of Reynolds et al. [7];

- the second one (point $M_{2}$, Figure 6) corresponds to the onset of transition boiling (the usual minimum film boiling point of the literature).

From the Farahat raw data, these two minima are given in Table 2 :

\begin{tabular}{|c|c|c|c|c|c|c|c|c|}
\hline Test & $\begin{array}{c}\Delta \mathrm{T}_{\mathrm{MFB}, 1} \\
(\mathrm{~K})\end{array}$ & $\begin{array}{c}\mathrm{q}_{\mathrm{MFB}, 1} \\
\left(10^{5} \mathrm{~W} \cdot \mathrm{m}^{-2}\right)\end{array}$ & $\begin{array}{c}\Delta \mathrm{T}_{\mathrm{MFB}, 2} \\
(\mathrm{~K})\end{array}$ & $\begin{array}{c}\mathrm{q}_{\mathrm{MFB}, 2} \\
\left(10^{5} \mathrm{~W} \cdot \mathrm{m}^{-2}\right)\end{array}$ & $\begin{array}{c}\Delta \mathrm{T}\left(\mathrm{M}_{12}\right) \\
(\mathrm{K})\end{array}$ & $\begin{array}{c}\mathrm{q}_{\left(\mathrm{M}_{12}\right)} \\
\left(10^{5} \mathrm{~W}^{-2}\right)\end{array}$ & $\begin{array}{c}\mathrm{q}_{\left(\mathrm{M}_{12}\right)} \\
/ \mathrm{q}_{\mathrm{MFB}, 1}\end{array}$ & $\begin{array}{c}\Delta \mathrm{T}_{\mathrm{MFB}} \text { (Farahat) } \\
(\mathrm{K})\end{array}$ \\
\hline 28 & & & 500 & 4.00 & & & & 489.2 \\
\hline 27 & & & 435 & 3.29 & & & & 489.2 \\
\hline 26 & 680 & 3.00 & 420 & 3.20 & 500 & 4.40 & 1.5 & 489.2 \\
\hline 25 & 660 & 3.00 & 450 & 3.30 & 600 & 4.50 & 1.5 & 489.2 \\
\hline 41 & 670 & 3.65 & 435 & 4.33 & 520 & 4.60 & 1.3 & 489.2 \\
\hline 36 & 650 & 3.00 & 445 & 3.35 & 560 & 4.40 & 1.5 & 611.2 \\
\hline 42 & 680 & 5.40 & 470 & 6.30 & 575 & 7.20 & 1.3 & 611.2 \\
\hline 35 & 735 & 3.45 & 410 & 3.85 & 590 & 5.40 & 1.6 & 611.2 \\
\hline 38 & 720 & 3.05 & 440 & 3.50 & 560 & 4.70 & 1.5 & 489.2 \\
\hline 32 & 650 & 3.10 & 470 & 3.15 & 600 & 4.60 & 1.5 & 550.2 \\
\hline 29 & 650 & 3.10 & 420 & 3.70 & 620 & 4.60 & 1.5 & 489.2 \\
\hline 33 & 790 & 3.55 & 440 & 4.35 & 630 & 6.00 & 1.7 & 672.2 \\
\hline 24 & 600 & 2.90 & 430 & 3.50 & 530 & 4.40 & 1.5 & 489.2 \\
\hline 39 & 680 & 3.70 & 485 & 4.15 & 570 & 5.50 & 1.5 & 550.2 \\
\hline
\end{tabular}

Table 2: The two minimum points in the Farahat boiling curves

In the frame of $\mathrm{FCl}$ studies for sodium-cooled reactors, it is important to precise the boiling curves around a liquid $\mathrm{UO}_{2}$ droplet moving into liquid sodium as a function of the fuel superheat $\Delta T_{\text {sat }}=$ $T_{S}-T_{\text {sat }}$ (where $T_{\mathrm{S}}$ is the sphere temperature), the coolant subcooling $\Delta T_{\text {sub }}=T_{\text {sat }}-T_{\infty}$, the 
sphere diameter $D_{S}$, the relative velocity $U_{\infty}$ and the pressure $P_{\infty}$. In particular, it is desirable to specify:

- the "stable" film boiling regime, i.e. to give the relation between the heat flux $q$ and the main governing parameters $\Delta T_{\text {sat }}, \Delta T_{\text {sub }}, D_{S}, U_{\infty}, P_{\infty}$, which can be modelled by a classical film boiling model with the hypothesis of smooth liquid vapor interface, as it has been done for the TREPAM water tests [10];

- the transition point to the "unstable" film boiling regime as a function of the same governing parameters. We recall that this point should be the one for the onset of thermally induced spontaneous $\mathrm{FCl}$ (no need of external trigger), that is the point at which premixing turns into explosion. This can be analyzed through a linear stability analysis of the above mentioned model. At the present time, such a model is not available so we propose a simplified analysis in which this transition will be determined by the transition from a "thick film regime" to a "thin film regime" as proposed by Reynolds et al. [7] for their tin-water experiments.

To do so:

- we draw the evolution of the vapor film thickness $\delta_{v}$ as a function of the subcooling, $\Delta T_{\text {sub }}$, for different sphere temperatures, which requires a model;

- we determine the transition from the "thick film region" (associated to stable film boiling) to the "thin film region" (associated with the unstable film boiling regime) by the intersection of the tangents of the $\delta_{v}$ curves drawn at the two extremities of the film boiling domain (dotted line in Figure 7);

- then during the cooling of a sphere in a given subcooled coolant, we reach the transition between the "stable" and "unstable" regimes at the intersection of the line $\Delta T_{\text {sub }}=$ constant and the transition line, which gives the sphere temperature at this transition.

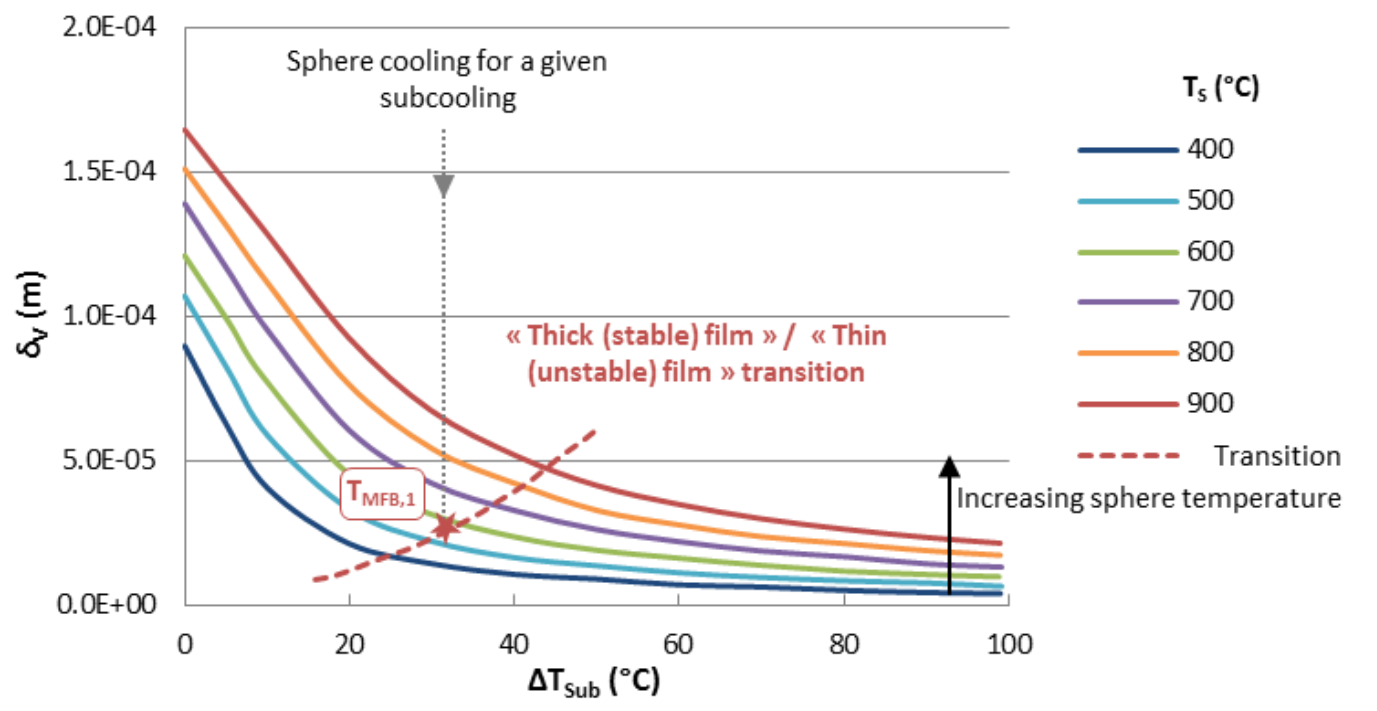

Figure 7: Simplified determination of the transition between the "stable" and "unstable" film boiling regimes Before using such a modeling for $\mathrm{UO}_{2}$-Na systems, for which no $\mathrm{FCl}$ zone (as the Reynolds et al. one) is available, we will apply it to the Reynolds experiment. 


\section{Validation of the simplified determination of the transition between stable and unstable film boiling regimes on the Reynolds et al. tin-water experiment}

A film boiling model is first needed to estimate the vapor film thickness with respect to the liquid coolant subcooling.

\subsection{Simplified stable film boiling around a sphere in the vicinity of the stagnation point}

This model is built with the following hypothesis:

H1 Potential liquid flow;

H2 Constant vapor film thickness, small relatively to the sphere radius;

H3 Laminar vapor flow;

H4 Smooth interface at $\mathrm{T}_{\text {sat }}(\mathrm{P})$;

H5 The inertial terms in the momentum equations as well as convective terms in the energy equations are negligible;

H6 The heat flux transmitted to the liquid is described by a classical forced convection correlation around a solid sphere at $T_{\text {sat }}$ i.e. the Boussinesq one:

$$
N u_{\text {Stag }}=2\left(\frac{3 P e}{\pi}\right)^{1 / 2} \text { with } P e=\frac{2 U_{\infty} R}{v_{L}} \quad \text { where } v_{L} \text { is the viscosity of the liquid. }
$$

H7 Radiation is neglected;

H8 Constant physical properties are taken at $\left(\mathrm{T}_{\mathrm{S}}+\mathrm{T}_{\mathrm{Sat}}\right) / 2$.

We consider the following coordinates system:

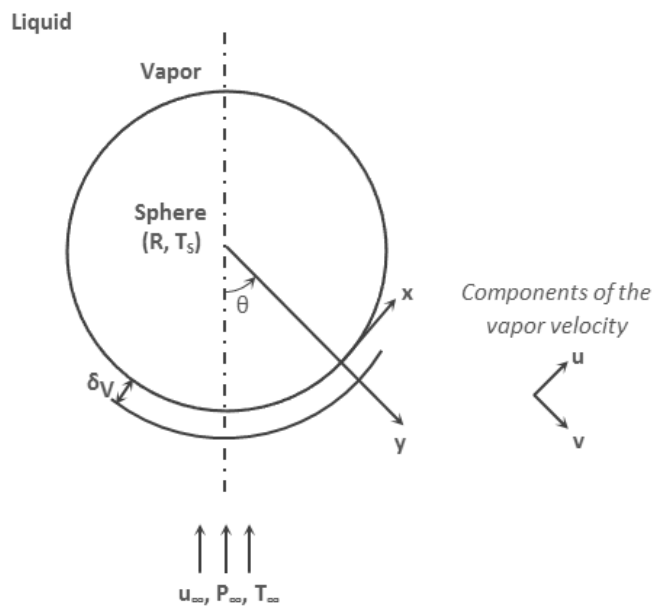

Figure 8: Coordinates system of the simplified film boiling model

The thickness $\delta_{v}$ of the vapor film is obtained from the interfacial energy balance:

$$
q_{c i}-q_{i L}=\dot{m}_{V} h_{L V} \quad \text { where: }
$$

$q_{c i}$ is the heat transferred from the sphere to the interface, given by: $q_{c i}=\frac{k_{V}}{\delta_{V}}\left(T_{S}-T_{S a t}\right)$ 
$q_{i L}$ is the heat transferred to the liquid from the interface:

$$
q_{i L}=\frac{k_{L} N u_{\text {Stag }}}{2 R}\left(T_{\text {Sat }}-T_{\infty}\right)=\frac{k_{L}}{R}\left(\frac{6 U_{\infty} R}{\pi \alpha_{L}}\right)^{1 / 2}\left(T_{\text {Sat }}-T_{\infty}\right)
$$

$\dot{m}_{V}=\rho_{V} v_{V i}, v_{V i}$ being the vapor radial velocity component at the interface that will be obtained solving the vapor flow from the $\mathrm{x}$ momentum equation which is written (using the coordinates system defined in Figure 8):

$$
0=-\frac{\partial P}{\partial x}+\mu_{V} \frac{\partial^{2} u_{V}}{\partial y^{2}}
$$

(with $\mathrm{H} 2, \mathrm{H} 5$ and considering a quasi-permanent regime)

Where the pressure gradient is such that:

$$
\frac{d P_{V}}{d x}=\frac{d P_{L}}{d x}=-\frac{9 \rho_{L} U_{\infty}^{2} x}{4 R^{2}}
$$

The $\mathrm{x}$ momentum equation is then solved using the two following boundary conditions:

$u_{V}(0)=0$ and $u_{V}\left(\delta_{V}\right)=u_{L}\left(\delta_{V}\right)=\frac{3}{2} \frac{U_{\infty} x}{R} \quad$ (with $\mathrm{H} 1$ and considering no slip at interface)

It is then obtained :

$$
u_{V}(y)=-\frac{9}{8} \frac{\rho_{L}}{\rho_{V}} \frac{U_{\infty}^{2} x}{v_{V} R^{2}} y^{2}+\frac{3}{2} \frac{u_{\infty} x}{\delta_{V} R}\left(1+\frac{3}{2} \frac{\rho_{L}}{\rho_{V}} \frac{U_{\infty} \delta_{V}^{2}}{v_{V} R}\right) y
$$

And the radial velocity is obtained from the vapor continuity equation:

$$
\begin{aligned}
& v_{V}(y)=-\frac{3}{8} \frac{\rho_{L}}{\rho_{V}} \frac{U_{\infty}^{2}}{v_{V} R^{2}} y^{3}-\frac{3}{4} \frac{U_{\infty}}{\delta_{V} R} y^{2}-\frac{9}{8} \frac{\rho_{L}}{\rho_{V}} \frac{U_{\infty}^{2}}{v_{V} R^{2}} \delta_{V} y^{2} \\
& \text { Then, } v_{V i}=v_{V}\left(\delta_{V}\right)=-\frac{3}{4} \frac{U_{\infty}}{R}\left(\delta_{V}+\frac{1}{4} \frac{\rho_{L}}{\rho_{V}} \frac{U_{\infty} \delta_{V}^{3}}{v_{V} R}\right)
\end{aligned}
$$

Introducing $v_{V i}$ in the interfacial energy balance leads to:

$$
\frac{k_{V}}{\delta_{V}}\left(T_{S}-T_{\text {Sat }}\right)-\frac{k_{L}}{R}\left(\frac{6 U_{\infty} R}{\pi \alpha_{L}}\right)^{1 / 2}\left(T_{\text {Sat }}-T_{\infty}\right)=\frac{3}{4} \frac{\rho_{V} U_{\infty} h_{L V}}{R}\left(\delta_{V}+\frac{1}{4} \frac{\rho_{L}}{\rho_{V}} \frac{U_{\infty} \delta_{V}^{3}}{v_{V} R}\right)
$$

which is an equation with $\delta_{v}$ as the only unknown.

\subsection{Application of the simplified model to the Reynolds et al. experiment}

In this experiment, $12 \mathrm{~g}$ tin droplets at different temperatures were dropped into water with different subcoolings to determine the region where spontaneous explosions occur. The above film boiling model is then applied to tin droplets of $7.3 \mathrm{~mm}$ diameter with a fall velocity $U_{\infty}=0.8 \mathrm{~m} . \mathrm{s}^{-1}$ and the "transition" is drawn. Results are provided in Figure 9. 


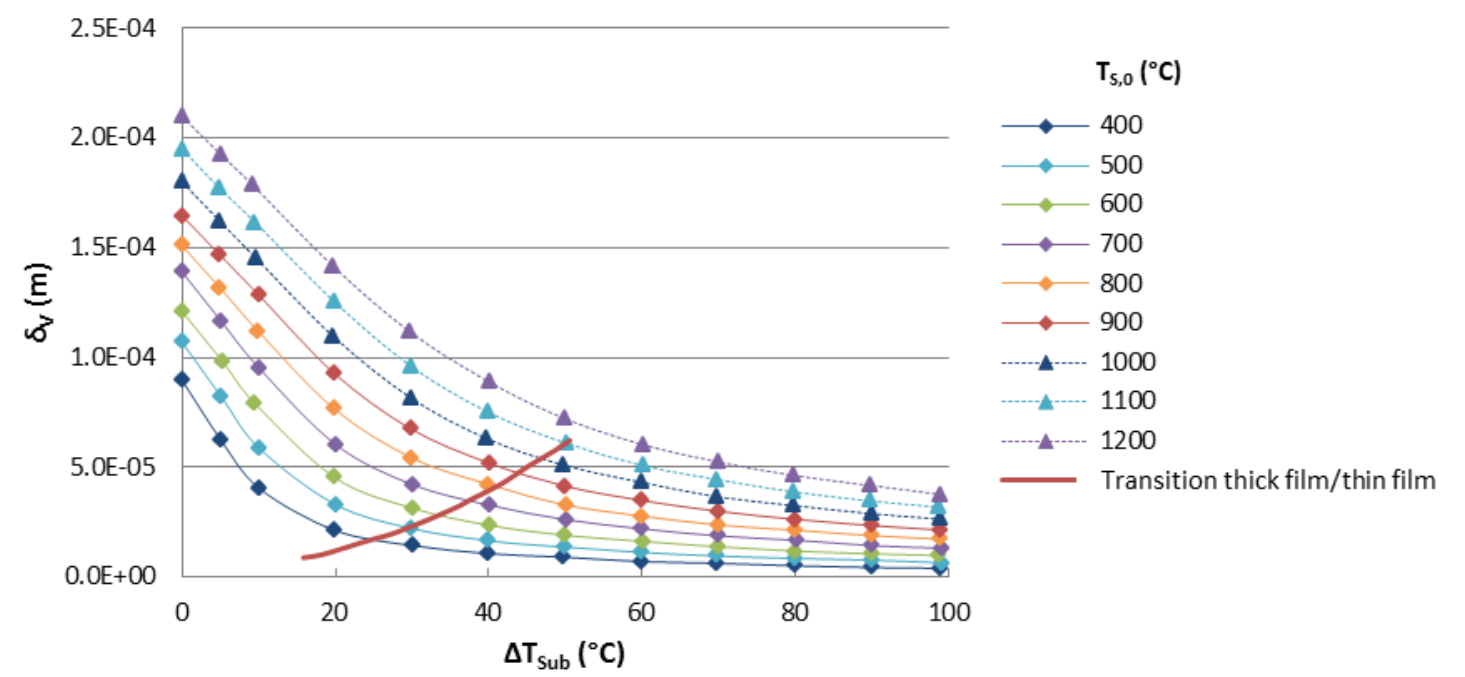

Figure 9: Variation of the vapor film thickness $\delta_{v}$ as a function of the subcooling for different droplet temperatures $\left(D_{s}=14.6 \mathrm{~mm}, U_{\infty}=0.8 \mathrm{~m} . \mathrm{s}^{-1}\right)$ - "Thick film"/"thin film" transition line

The "thick film"/"thin film" transition points determine by the model are then drawn on the TIZ reported by Reynolds et al., showing a good agreement with the experimental TIZ diagonal boundary (Figure 10):

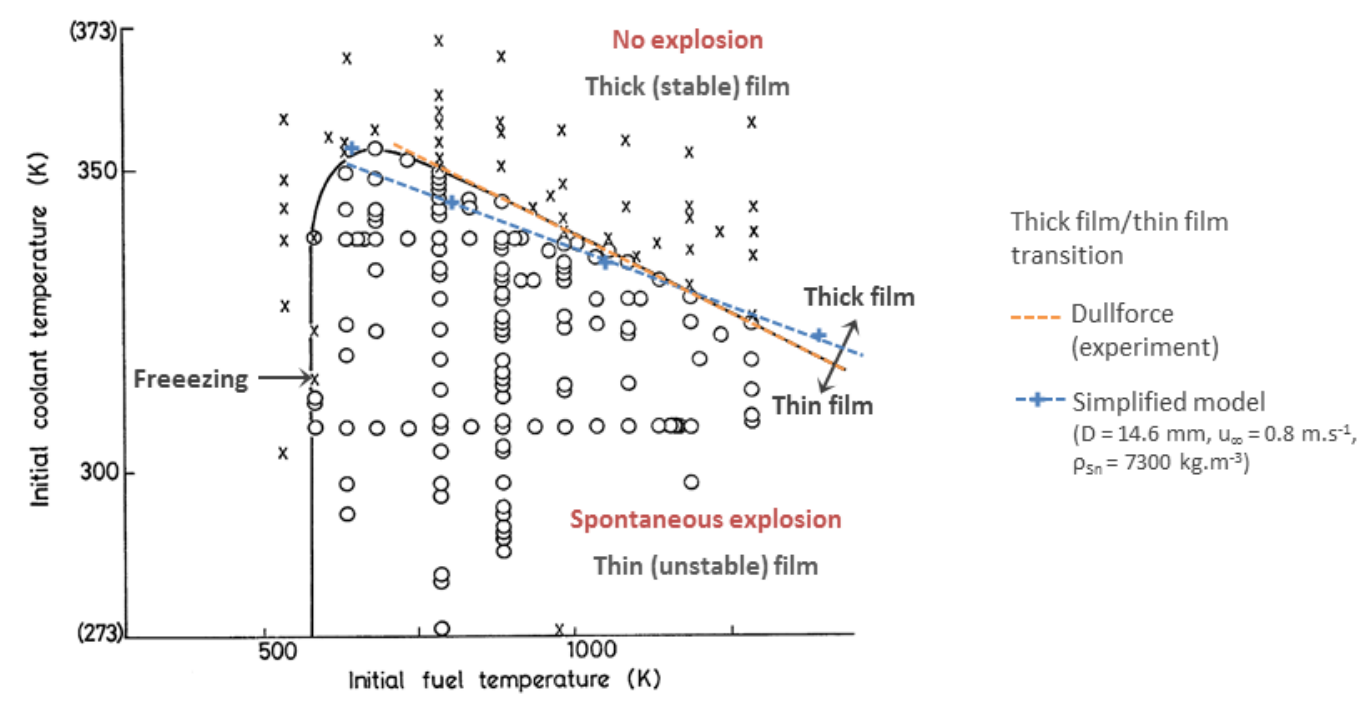

Figure 10: Comparison of the transition "thick film"/"thin film" determined by the simplified model with the experimental diagonal TIZ boundary obtained by Reynolds et al.

\section{Application of the simplified approach to the $\mathrm{UO}_{2}-\mathrm{Na}$ system}

The validation of the simplified model against the $\mathrm{Sn}-\mathrm{H}_{2} \mathrm{O}$ system of Reynolds et al. allows us to apply it to the $\mathrm{UO}_{2}-\mathrm{Na}$ couple in the absence of experimental results or theoretical models. The estimation of the transition "thick film" (stable)/"thin film" (unstable) will provide us with the fuel temperature at which spontaneous explosions would occur (if the melt was still sufficiently liquid at this temperature) indicating the end of the premixing sequence.

Here again, a vapor film model is needed. The model developed by Le Belguet [11] is applied. It is an integral model using the method developed by de Malmazet [12] which allows to use the same model for natural and forced convection, from saturation to large subcooling conditions (the model 
can be used with very small relative velocities $U_{\infty}$ and/or very small subcoolings). The de Malmazet model is validated against the TREPAM experiment [10] and against many other experiments around spheres and cylinders in which stable film boiling is observed [12].

To verify the validity of the Le Belguet stable film boiling model, it has been compared with the only sodium film boiling experiment known at the present time, i.e. the Farahat natural convection one. Looking at Figure 11, a good agreement is found between the model and the experimental results corrected by the rod effect (dotted line) in what is called the "stable film boiling regime". In this figure are shown the "raw" Farahat data $\left(\mathrm{q}_{\mathrm{exp}}\right)$, the corrected ones $\left(\mathrm{q}_{\mathrm{exp}, \mathrm{rod}}\right)$ and the mean heat flux lost by the sphere $\left(q_{t o t m}\right)$ which is the total lost heat flux, integrated along the sphere and divided by the sphere surface.

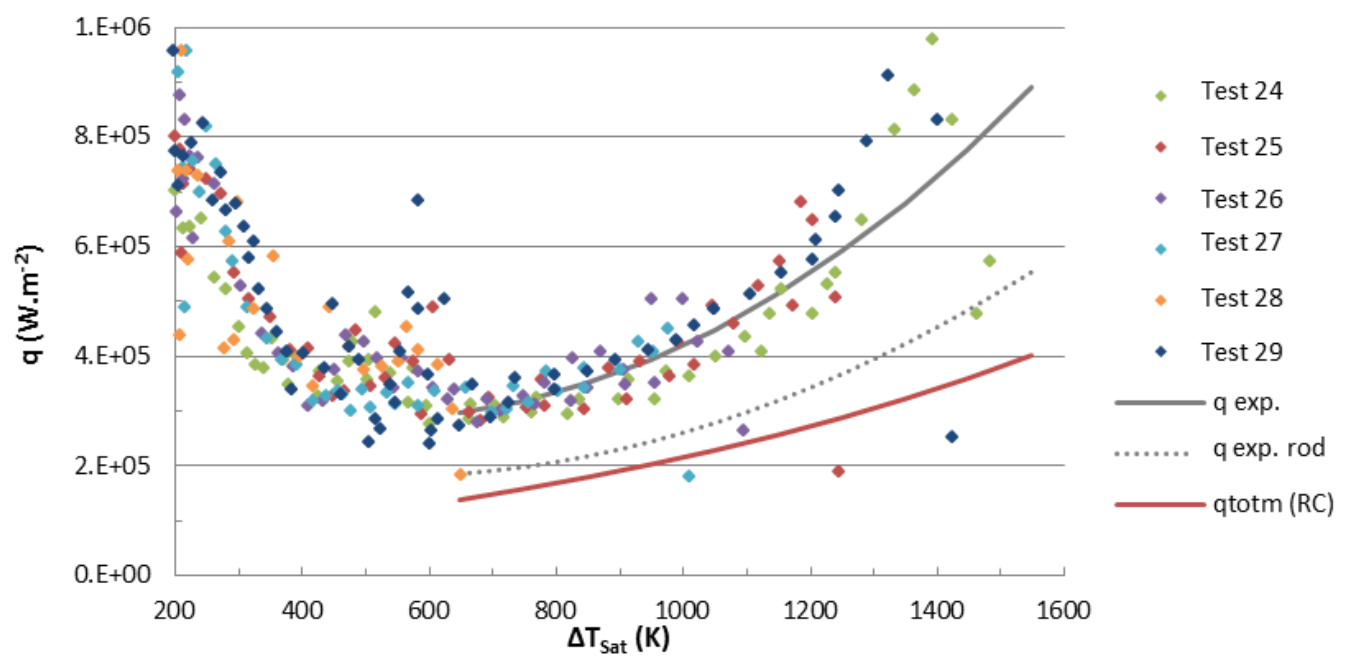

a. $D_{s}=2.54 \mathrm{~cm}, \Delta \mathrm{T}_{\text {sub }}=4.1 \mathrm{~K}$ and $\mathrm{U}_{\infty}=10^{-4} \mathrm{~m} \cdot \mathrm{s}^{-1}$

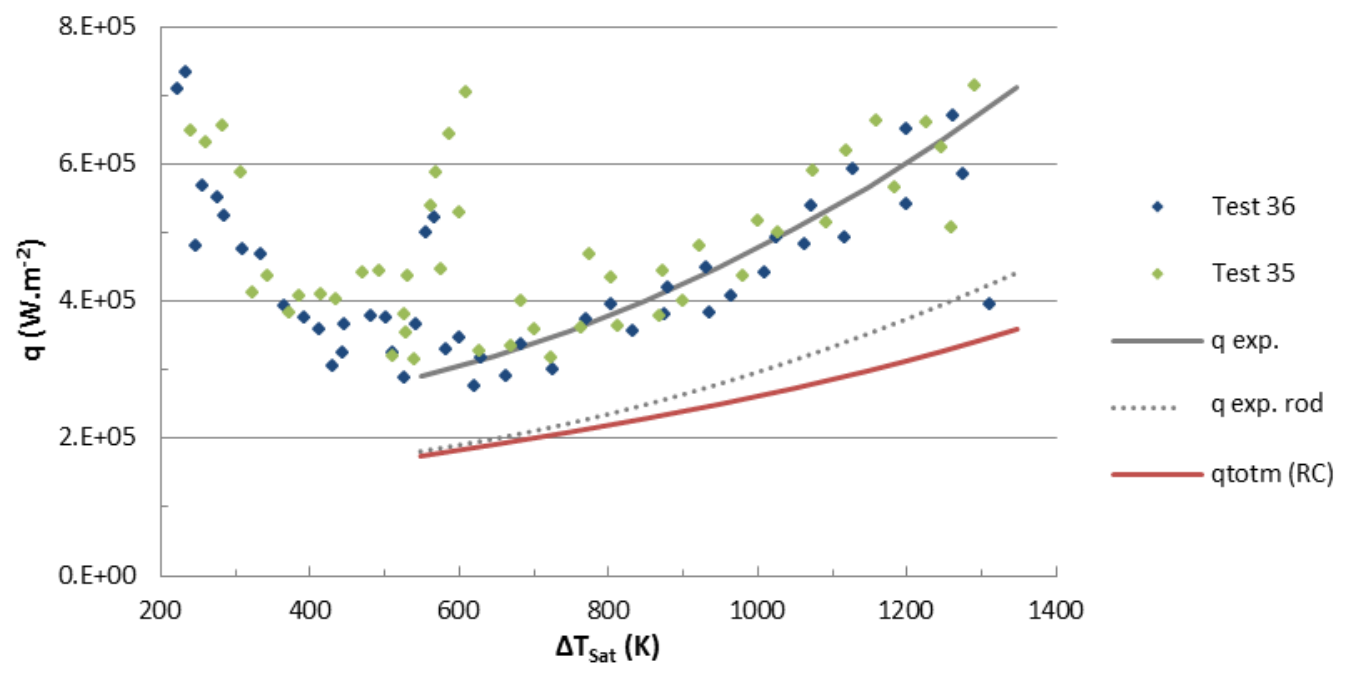

b. $D_{s}=2.54 \mathrm{~cm}, \Delta T_{\text {sub }}=14.1 \mathrm{~K}, \mathrm{U}_{\infty}=10^{-4} \mathrm{~m} \cdot \mathrm{s}^{-1}$ 


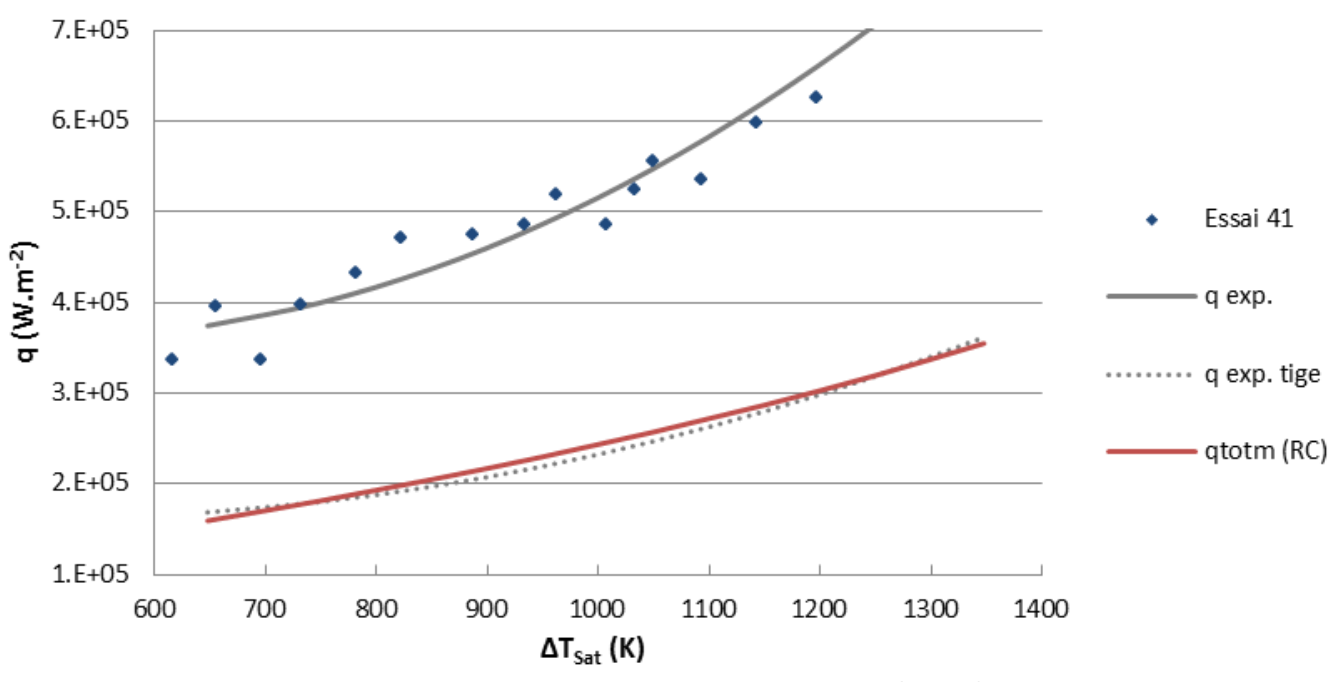

c. $D_{s}=1.27 \mathrm{~cm}, \Delta \mathrm{T}_{\text {sub }}=4.1 \mathrm{~K}, \mathrm{U}_{\infty}=10^{-4} \mathrm{~m} . \mathrm{s}^{-1}$

Figure 11: Comparison between the Farahat data corrected by the "rod effect" and the Le Belguet integral model

In this figure, the agreement between the corrected experimental flux (rod effect) and the calculated one is acceptable. During the early part of the cooling (high $\Delta \mathrm{T}_{\text {sat }}$ ), part of the difference may be explained by the plunging motion of the sphere, inducing relative motions which increase heat transfer while the calculated flux used a very small relative velocity $\left(U_{\infty}=10^{-4} \mathrm{~m} \cdot \mathrm{s}^{-1}\right)$.

So this model will be applied to calculate the vapor film thickness at the stagnation point on the sphere for different sphere temperatures, as a function of the sodium subcooling, from saturation to the maximum subcooling allowing the film boiling regime i.e. $\Delta \mathrm{T}_{\text {sub,max }}$.

This maximum subcooling is obtained from correlations giving the classical minimum film boiling temperature $T_{\text {MFB }}\left(M_{2}\right.$ point on Figure 6$)$. Very few is known about this minimum film boiling temperature. A review of what is known can be found in Le Belguet thesis [11]. Two correlations have been selected here:

- the semi empirical correlation provided by Henry [13];

- the one implemented in the SIMMER code by Kondo et al. [14].

Details about these correlations can also be found in [11]. However it has to be mentioned that these correlations do not take into account the effect of the sphere diameter which was clearly shown for example by Gunnerson [15] and Hendricks [16]. When the diameter increases, the minimum film boiling temperature decreases first and then jumps to a higher, about constant, value. This is consistent with the fact that, with large diameters, instabilities can grow at the vapor-liquid interface leading to liquid-solid contacts so that a higher sphere temperature is needed to sustain stable film boiling. Results given by the Le Belguet model with these two evaluations of $\mathrm{T}_{\mathrm{MFB}}$ are shown in Figure 12. 

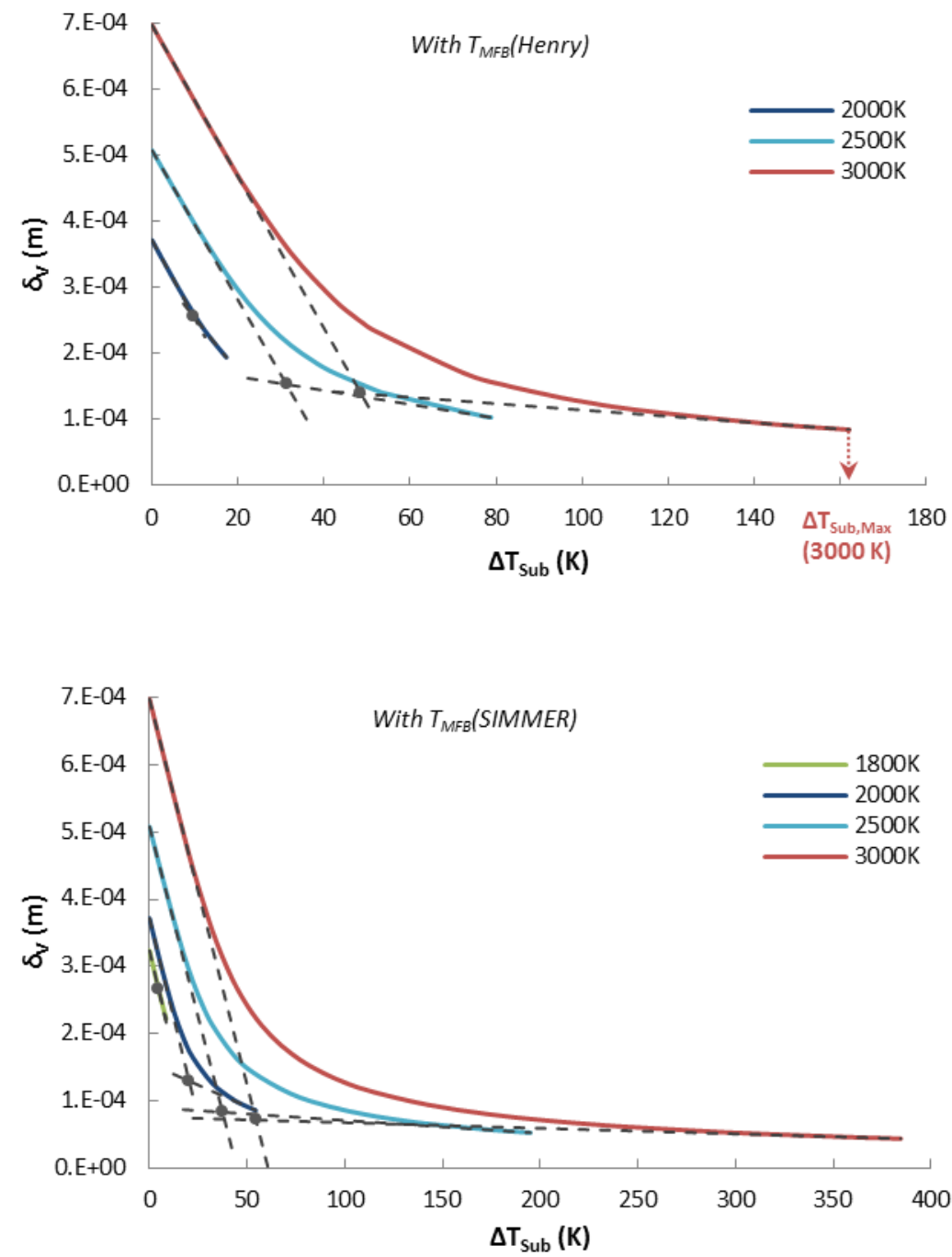

Figure 12: Evolution of vapor film thickness as function subcooling for different sphere temperatures with two different estimations of the minimum film boiling temperature.

Drawing the transition "thick film"/"thin film" line, it is then possible to derive the fuel temperature at which stable to unstable film boiling regime occurs (the $\mathrm{M}_{1}$ point corresponding to $\mathrm{T}_{\mathrm{MFB} 1}$ in Figure 6). Results are shown in Figure 13. 


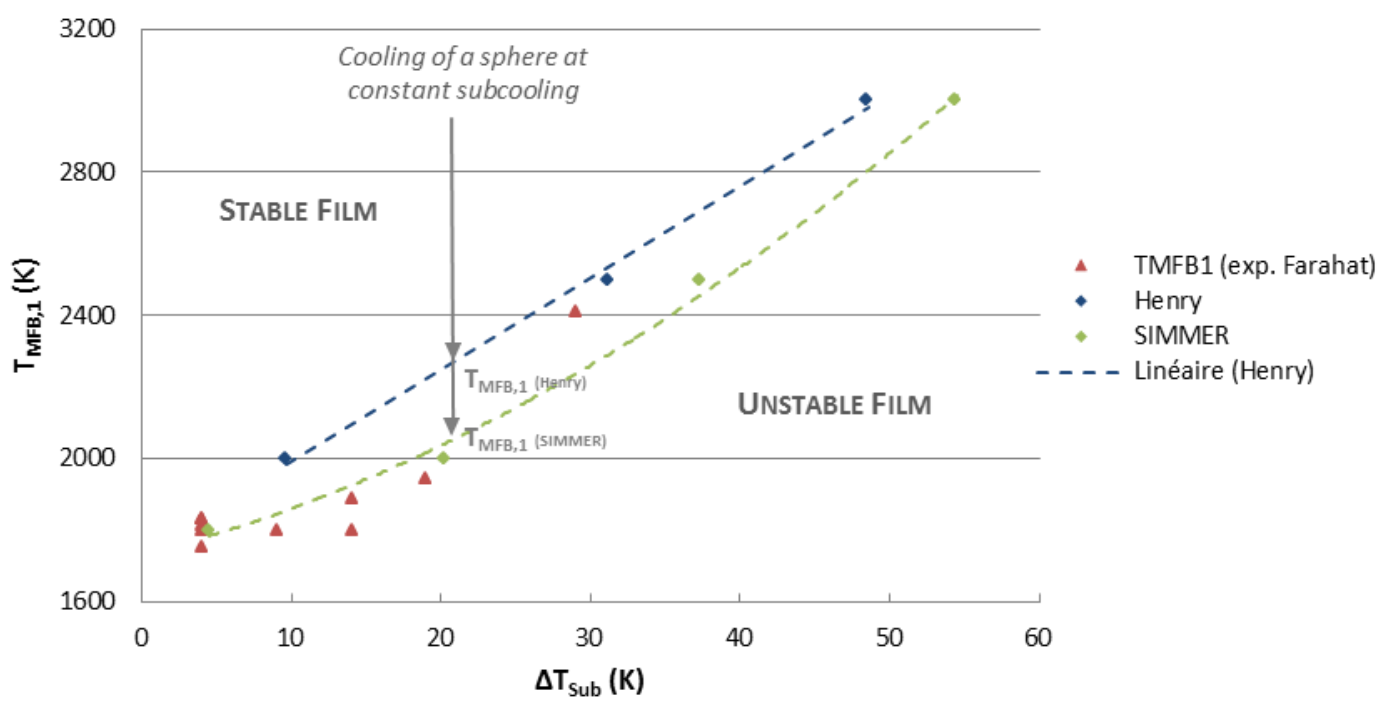

Figure 13: Results of the determination of the fuel temperature at which stable/unstable film boiling transition occurs for the tantalum sphere of Farahat in natural convection. Comparison with the transition points observed on Farahat results (M1 in Figure 6)

As the results obtained with the simplified model give a pretty good agreement with the Farahat results, the same method has been applied to the $\mathrm{UO}_{2}$-Na system. In Table 3, the fuel temperature transitions are presented in the case of a $5 \mathrm{~mm}$ diameter sphere of $\mathrm{UO}_{2}$ in sodium flow, with $\mathrm{U}_{\infty}=2$ $\mathrm{m} . \mathrm{s}^{-1}$ according to the choice of the minimum film boiling temperature correlation:

\begin{tabular}{|l|c|c|c|c|}
\cline { 2 - 4 } \multicolumn{1}{c|}{} & \multicolumn{2}{c|}{$\Delta T_{\text {sub }}=10 \mathrm{~K}$} & \multicolumn{2}{c|}{$\Delta \mathrm{T}_{\text {sub }}=\mathbf{1 5} \mathrm{K}$} \\
\cline { 2 - 5 } \multicolumn{1}{c|}{} & $\mathrm{T}_{\mathrm{MFB}}$ Henry & $\mathrm{T}_{\mathrm{MFB}}$ SIMMER & $\mathrm{T}_{\text {MFB }}$ Henry & $\mathrm{T}_{\text {MFB }}$ SIMMER \\
\hline $\begin{array}{l}\text { Fuel temperature at the } \\
\text { stable/unstable film boiling } \\
\text { transition }\end{array}$ & $2110 \mathrm{~K}$ & $2680 \mathrm{~K}$ & $3060 \mathrm{~K}$ & $3260 \mathrm{~K}$ \\
\hline
\end{tabular}

Table 3: Results of the simplified model for $\mathrm{UO}_{2}-\mathrm{Na}$ system in forced convection

This type of calculations clearly shows the important effect of the pressure on this transition temperature. The stabilizing effect of the pressure on the film is observed as the transition temperature decreases when the pressure increases, as shown in table 4.

\begin{tabular}{|c|c|c|c|}
\cline { 2 - 4 } \multicolumn{1}{c|}{} & \multicolumn{2}{c|}{$\Delta \mathbf{T}_{\text {sub }}(\mathrm{K})$} \\
\hline $\begin{array}{c}\text { Pressure } \\
n\end{array}$ & 10 & 20 & 40 \\
\hline $\mathrm{P}=1$ bar & 2100 & 4060 & 5980 \\
\hline $\mathrm{P}=2$ bar & 1908 & 3170 & 4144 \\
\hline $\mathrm{P}=5$ bar & 1581 & 2435 & 3350 \\
\hline $\mathrm{P}=10$ bar & 1470 & 2096 & 569 \\
\hline
\end{tabular}

Table 4: Transition temperature (with Henry correlation) for different subcoolings and pressures for a $\mathrm{UO}_{2}$ sphere of $5 \mathrm{~mm}$ diameter in a relative flow of sodium at $U=2 \mathrm{~m} . \mathrm{s}^{-1}$ 
Such a sphere would be in stable film boiling - then allowing mixing - for a subcooling smaller than $17 \mathrm{~K}$ at 1 bar, $23 \mathrm{~K}$ at 2 bar, $32 \mathrm{~K}$ at 5 bar and $42 \mathrm{~K}$ at 10 bar.

\section{Conclusions}

Cooling experiments of spheres and cylinders in the film boiling regime have shown the existence of two film boiling regimes:

- one with low heat fluxes; this regime is favored by high superheat, small subcooling, low diameter, low relative velocity and high pressure;

- it is followed, during the cooling, by a higher heat flux regime in which contacts between the coolant and the hot material are observed.

If these contacts occur when the hot material is still liquid, they are likely to trigger a steam explosion as these observed when they are induced by the film destabilization by a pressure wave. This idea has been validated on the tin-water droplet experiments of Reynolds et al. [7].

With sodium as a coolant, revisiting the natural convection film boiling experiment of Farahat has provided evidence of the occurrence of these two film boiling regimes (they were not mentioned by Farahat, see Figure 5). Unfortunately, the results of this experiment are questionable. At least the influence of the sustaining rod is not evoked and according to Hässler [9], it could be of importance.

It would then be desirable to perform quenching experiments starting in the film boiling with sodium as the coolant. These experiments should be performed in forced convection with superheat, subcooling, sphere diameter, relative velocity and pressure as the governing parameters. In order to observe the two film boiling regimes, the hot material should be chosen to remain solid during the quenching to allow the high heat flux regime without explosions occurring after the transition. Heat fluxes measured in the "stable" regime should be compared to models similar to the one developed by Le Belguet in order to provide better correlations to describe the cooling of such spheres in a premixing sequence of a $\mathrm{FCl}$. At this time, we can mention that for the $\mathrm{UO}_{2}-\mathrm{H}_{2} \mathrm{O}$ systems the wellknown Esptein-Hauser correlation [17], which is often used in $\mathrm{FCl}$ codes, overestimates up to factor of 3 the measured Nusselt number in the TREPAM experiments [18], all performed in the stable film boiling regime. The measured transition temperature - the one at which a spontaneous explosion could be triggered - should be compared to a model including the development of instabilities at the vapor-liquid interface. This could be performed by the mean of a linear stability analysis of a stable film boiling model.

\section{References}

[1] Berthoud G., Jacobs H., Knowles J.B., 1994, "Large Scale Fuel Sodium interaction: Synthesis of European programs" Report WAC (94) - Di 375, Contract with European commission/DG XII/FNETNU-920069

[2] Honda H., Takamatsu H., Yamashiro H., 1992, "Heat transfer characteristics during rapid quenching of a thin wire in water", Heat Transfer Japanese Research, 21 (8), 773-791

[3] Berthoud G., Gros d'Aillon L., 2009, "Film boiling heat transfer around a very high temperature thin wire immersed into water at pressure from 1 to 210 bar : experimental results and analysis", International Journal of Thermal Science, 48, 1728-1740 
[4] Kikushi Y., Ebisu T., Michiyoshi I., 1992, "Measurements of liquid-solid contacts in film boiling", International Journal of Heat and Mass Transfer, 35(6), 1589-1594

[5] Honda H., Takamatsu H., Yamashiro H., 1995, "Minimum Heat flux point and liquid-solid contacts during rapid quenching of a thin wire", Heat Transfer Japanese Research, 24(6), 517-537

[6] Sher I., Harari R., Reshef R., Sher E., 2012, "Film boiling collapse in solid spheres immersed in a subcooled liquid", Applied Thermal Engineering, 36, 219-226

[7] Reynolds J.A., Dullforce R.S., Peckover R.S., Vaughan G.J., 1976, "FCl studies-Some basic studies at Culham Laboratory", CLM/RR/S2/7, 3th special Meeting on sodium fuel interactions in fast reactors", Tokyo

[8] Farahat M-M-X, 1971, "Transient boiling heat transfer from spheres to sodium", PhD thesis, Argonne National Laboratory, University of Alexandria

[9] Hässler M., 1998, "Experimentelle Untersuchungen zum Wärmeübergang und Strömungswiderstand beim Filmsieden an sehr heißen Kugeln (Experimental investigation of heat transfer and drag during film boiling on very hot spheres)", FZK, Karlsruhe, Allemagne

[10] De Malmazet E., Berthoud G., 2009, "Convection film boiling on horizontal cylinders", International Journal of Heat and Mass Transfer, 52, 4731-4747

[11] Le Belguet A., 2013, "Etude de l'ébullition en film du sodium autour d'une sphère à haute temperature", PhD Thesis, Grenoble University (spécialité Mécanique des fluides Energétique, Procédés)

[12] De Malmazet E., Berthoud G., 2009, "Etude de la fragmentation de gouttes chaudes en ébullition en film dans écoulement d'eau", Ph D Thesis, Institut Polytechnique de Grenoble

[13] Henry R.E., 1974, "A correlation for the minimum film boiling temperature", Heat Transfer Research and Design, AICHE Symposium series, 138 (70), 81-90

[14] Kondo S., Konishi K., Lsokaia M., Imohoria S., Furutania A., Brear D., 1995, “Experimental study on simulated molten jet-coolant interaction", Nuclear Engineering and Design, 155, 73-84

[15] Gunnerson F.S., Gronenberg A.W., 1979, "Film boiling destabilization from Hydrodynamic and thermodynamic considerations with application to the understanding of vapor explosion phenomena", Technical Report NE-66 (79) NRC-318-1 University of New Mexico

[16] Hendricks R.C., Baumeister K.J., 1967, "Film boiling from submerged spheres", NASA Technical Paper TN D-5124, Washington DC

[17] Epstein M., Hauser G.M., 1980, "Subcooled forced convection film boiling in the forward stagnation region of a sphere or cylinder", International Journal of Heat and Mass Transfer, 23, 179181

[18] Berthoud G., 2009, "Use of the TREPAM hot wire quenching test results for modelling heat transfer between fuel and coolant in FCl codes", Nuclear Engineering and Design, 239(12), 2908-2915 